\title{
Italian Children Go to School with a Hydration Deficit
}

\section{Baroukh M Assael ${ }^{1 *}$, Marco Cipolli', llaria Meneghelli', Marianna Passiu' ${ }^{1}$, Sira Cordioli ${ }^{1}$, Gloria Tridello ${ }^{1}$, Eve M. Lepicard ${ }^{2}$, Florence} Constant $^{3}$, Nasrine Hawili ${ }^{3}$ and Gérard Friedlander ${ }^{4}$

${ }^{1}$ Centro Ricerca Clinica Fibrosi Cistica, Ospedale Civile Maggiore, Azienda Ospedaliera Universitaria Integrata Verona, P.le Stefani, 1, 37126 Verona, Italy ${ }^{2}$ Institute for European Expertise in Physiology, 21 rue Leblanc, 75015 Paris, France

${ }^{3}$ Nestlé Waters M.T., 12 boulevard Garibaldi, 92793 Issy Les Moulineaux, France

${ }^{4}$ Department of Physiology, European Hospital Georges-Pompidou, AP-HP, Paris, France / Growth and Signaling Research Center Inserm U845, Paris Descartes University, Paris, France

\begin{abstract}
Background and aims: Fluid requirements of children vary as a function of gender and age. To our knowledge, there is very little literature on the hydration status of Italian children. We assessed morning hydration status in a large sample of 515 Italian school children aged 9 to 11 years.
\end{abstract}

Methods: Recruited children completed a questionnaire on fluid and food intake at breakfast and collected a urine sample the very same day after breakfast. Breakfast food and fluid nutritional composition was analysed and urine osmolality was measured using a cryoscopic osmometer.

Results: More than two thirds of the children had urine osmolality above $800 \mathrm{mOsmol} / \mathrm{kg}$ while $35.0 \%$ had urine osmolality over $1000 \mathrm{mOsmol} / \mathrm{kg}$. This was more frequent in boys than in girls $(71.9 \%$ versus $62.5 \% ; p=0.02)$. Total water intake (water coming from both food and fluid) as well as total fluid intake at breakfast were significantly and inversely correlated with urine osmolality.

Conclusions: Almost two thirds of the children in this large cohort had evidence of a hydration deficit when they went to school in the morning, despite breakfast intake. Children's fluid intake at breakfast does not suffice to maintain an adequate hydration status for the whole morning.

Keywords: Children; Hydration; Urine osmolality; Water

\section{Introduction}

Maintenance of an adequate hydration status in children is critical. Total body water volume ranges from 2.9 liters in children aged 1.5 months to 22.6 liters in 11-year-olds [1]. Children are more prone to dehydration than adults because they have a greater body surface: body weight ratio and their excretion and urine concentration abilities are not yet maximal, especially at an early age [2]. Consequently, children require more water on a body weight basis than adults [3-5] and their fluid requirements vary as a function of gender and age. Gender, age clusters, and definitions of recommended daily water intakes vary widely between countries and continents [6]. The Institute of Medicine recommends $2400 \mathrm{~mL} /$ day and $2100 \mathrm{~mL} /$ day of total water, respectively, for American boys and girls aged 9 to 13 years [7]. For children aged 9 to 13 years, EFSA recommends $2100 \mathrm{~mL} /$ day for boys and $1900 \mathrm{~mL} /$ day for girls of total water intake. Of note is the fact that fluid intake recommendations are not the same between boys and girls before puberty and differences in water homeostasis can already be seen before the age of 13 years [6].

Several observational studies have assessed the hydration status in children by assessing daily fluid intake in large cohorts and in various countries. In Germany, in the DONALD study, Ebner et al. observed that girls and boys aged 9 to 13 years had a total daily water intake of $1891 \mathrm{~g}$ and $1671 \mathrm{~g}$, respectively (including drinking water, other beverages, water coming from food and from metabolism) [8]. In a sample of 566 French children aged 6 to 11 years, Bellisle et al. found that total fluid intake was $1046 \pm 42 \mathrm{~mL}$ per day with some children drinking as little as $372.9 \mathrm{~mL}$ per day [9]. Other studies carried out in Canada, Guatemala and the USA reached the same conclusions: water intake in children falls short of recommendations worldwide and is probably insufficient to maintain adequate hydration [10-12]. Is it the case in Italy? To the best of our knowledge, no data are available on the hydration status and the fluid intake of Italian children.
Children who drink too little to meet their fluid requirements are likely to become dehydrated and have elevated urine osmolality. Prevalence of elevated urinary osmolality in children has been reported in several countries with various climatic conditions. In Germany, a sample of children of the DONALD study, aged 3-18 years, had a mean $24 \mathrm{~h}$ urine osmolality of $801 \mathrm{mosmol} / \mathrm{kg}$ [13]. In France, a recent study on a large sample of 529 children aged 9 to 11 years, showed that $62 \%$ of the children had a random urine osmolality over $800 \mathrm{mosmol} / \mathrm{kg}$ of water after breakfast intake and $22.7 \%$ over $1.000 \mathrm{mosmol} / \mathrm{kg}$ of water [14]. In USA, an elevated urine osmolality (over $800 \mathrm{mosmol} / \mathrm{kg}$ ) was observed in $63 \%$ and $66 \%$ of children living respectively in Los Angeles and New York City [15]. In Israël with dry and hot climatic conditions, Bar-David et al. have observed that most of the healthy Jewish children included in their study had a urine osmolality over $800 \mathrm{mosmol} / \mathrm{kg}$ on arrival at school [16] and/or at noontime at school [16-19]. This body of data further strengthens the hypothesis of high prevalence of mild hydration deficit, reflected by a urinary osmolality over $800 \mathrm{mosmol} / \mathrm{kg}$ of water $[13,16]$, in schoolchildren in various countries and highlights the needs for further investigation.

Therefore, we measured morning urine osmolality as well as food and fluid intake at breakfast in a large sample of 515 Italian children aged 9 to 11 years.

*Corresponding author: Baroukh Maurice Assael, Professor, Centro Ricerca Clinica Fibrosi Cistica, Ospedale Civile Maggiore, Azienda Ospedaliera Universitaria Integrata Verona, P.le Stefani, 1, 37126 Verona, Italy, Tel: +00 390458122370 Fax: +00 39045812 2042; E-mail: mailto:baroukh.assael@ospedaleuniverona.it

Received May 15, 2012; Accepted May 29, 2012; Published May 31, 2012

Citation: Assael BM, Cipolli M, Meneghelli I, Passiu M, Cordioli S, et al. (2012) Italian Children Go to School with a Hydration Deficit. J Nutr Disorders Ther 2:114 doi:10.4172/2161-0509.1000114

Copyright: (c) 2012 Assael BM, et al. This is an open-access article distributed under the terms of the Creative Commons Attribution License, which permits unrestricted use, distribution, and reproduction in any medium, provided the original author and source are credited. 


\section{Material and Methods}

\section{Subject recruitment}

The study protocol was approved by the ethical committee of the Dipartimento Interaziendale di Farmacia of the Azienda Ospedaliera Universitaria Integrata Verona, Italy, on the 22nd of December, 2010. The population selected for sampling comprised healthy children attending school. It was necessary to select a specific subgroup of children because water requirements vary considerably according to age. Therefore, we chose an age range of 9.0 to 11.0 years. We set 11 years as the upper limit because puberty induces changes in nutritional behavior. To avoid population heterogeneity, we kept the age range small by setting the lower limit at 9 years. The aim was to recruit all children within a short time period outside the summer season so as to avoid dehydration due to climatic conditions. Consequently, recruitment and collection of urine samples took place between 02 February and 19 may 2011. Children were recruited on a voluntary basis through 12 primary schools from the city of Verona and vicinity. This area includes urban as well as rural populations from various socioeconomic strata. All children were given a study pack to take home. The pack contained a study information document, a parent and child consent form, a questionnaire covering demographic information, use of medications, exercise and diet, and included a urine sample container. Children returned study materials, including the urine sample, to the school administrative staff or teachers on designated days.

Children were included if both parents had signed the informed consent and if they fulfilled the inclusion criteria, which included a usual intake of at least two main meals per day. Children were excluded if they currently or previously had a metabolic or digestive disease (with the exception of appendectomy) or renal disease (renal insufficiency etc.), if they had fever, or if they were prescribed a local or systemic treatment likely to interfere with evaluation of the study parameters, including hydration state in particular (diuretic treatment or treatment interfering with metabolism and eating behaviour). To evaluate compliance, children and parents had to write the date and time of urine collection in two separate places: once on the label of the urine collection flasks and once on the breakfast questionnaire. From these data, we were able to check whether the urine sample was collected after breakfast or after another meal. If urine was collected after another meal, children were excluded. Moreover, we calculated the time interval between breakfast and urine collection to check whether the procedure had been correctly followed.

A total of 523 children participated in the study. Of these, 8 were excluded because of their age, or because either the food and fluid questionnaire or the urine sample was missing.

\section{Dietary Measurements}

Dietary intake was determined using an estimated diary method, where children and/or parents recorded all food and drink consumed at breakfast, or the last meal of the previous day in the case of children not consuming breakfast, including brand name and portion size (household measures or package weight). Children also recorded time of breakfast in relation to time of urine sample.

Dietary data were entered in a Metadieta Diet Software (Meteda, Italy) which converts the amount of food eaten into individual energy and macronutrients and assigns consumed foods into food groups and subgroups. Smoothies, milkshakes, and drinking yoghurts were considered beverages. Drinking water consisted of tap, spring, natural mineral waters or unsweetened sparkling waters. Milk added to cereal was considered drink. The potential renal solute load (PRSL) was calculated according to the Fomon equation: PRSL $(\mathrm{mmol})=5.7^{*}(\mathrm{~g}$ of protein $)+(\mathrm{mg}$ of sodium $/ 23)+(\mathrm{mg}$ of potassium $/ 39)+0.55^{*}(\mathrm{mg}$ of phosphorus/31) [20].

\section{Urine sample}

Children were asked to collect a urine sample at home, 30 minutes after breakfast (the first void of the morning was not collected; they were instructed to collect their second void of the morning). Time of urine collection was recorded directly on the flask label which was brought to school on the morning of collection, if this was a school day, or alternatively stored in a cool place if the sample was collected on a weekend. After collection at school by the study team, urine samples were aliquoted and stored at $-20^{\circ} \mathrm{C}$ for 5 days maximum after sample collection, until analysis, which was masked to clinical data.

\section{Measurement of urine osmolality}

Urine osmolality was measured in the same central laboratory of the Laboratorio Analisi - B.go Roma, Policlinico G. B. Rossi - Azienda Ospedaliera Universitaria Integrata Verona, using a freezing point osmometer.

\section{Statistics}

We estimated that a sample size of 500 participants would be needed, based on previous results from a large US cohort showing a high prevalence of elevated urine osmolality defined as a value above $800 \mathrm{mOsmol} / \mathrm{kg}$. We assumed this prevalence to be the same in our cohort, with an accuracy of 5\% and a $95 \%$ confidence interval and concluded that at least $n=384$ subjects were to be included. We adjusted this sample size to a minimum of $\mathrm{n}=500$.

Descriptive data included Fisher's test, t-test or ANOVA comparisons between girls and boys for several variables: water intake according to various sources of water available at breakfast as well as urine osmolality. A linear regression was performed to analyse the breakfast determinants of osmolality, where osmolality depends on cohort characteristics (age, sex, height, weight, school, medical treatment) and breakfast composition (total water intake, kilocalories, etc.). Sex, medical treatment and schools were considered as categorical variables by using dummies. Multiple logistic regression was used to estimate the relationship between total water intake and the likelihood of having an osmolality over $800 \mathrm{mOsmol} / \mathrm{kg}$ by calculating the Odds Ratios (OR) and the corresponding 95\% Confidence Intervals (CIs); $p$ values associated with tests for linear trends in the OR are also provided. The effects of potential confounders (sex, weight, height, age, school) were examined by including these variables in the logistic regression models. Any missing values were assigned to a separate category.

All statistical analyses were carried out using SAS software for Windows. Significance was accepted at an alpha level of 0.05 .

\section{Results}

\section{Description of the cohort}

The cohort comprised an almost equal number of girls $(n=256)$ and boys $(\mathrm{n}=259)$ (Table 1$)$. The mean age was $10.1 \pm 0.03$ years. The mean body height, $144.5 \pm 8.4 \mathrm{~cm}$, and mean body weight, 37.8 $\pm 8.1 \mathrm{~kg}$, correspond both to reference values previously observed by Cacciari et al. in North Italy in 2002 [21]. Weight and height were quite similar between girls and boys. Using International Obesity Task Force cut-offs, we observed that $38.3 \%$ of the children in the cohort were 
Citation: Assael BM, Cipolli M, Meneghelli I, Passiu M, Cordioli S, et al. (2012) Italian Children Go to School with a Hydration Deficit. J Nutr Disorders Ther 2:114. doi:10.4172/2161-0509.1000114

Page 3 of 6

overweight and $22.5 \%$ were obese. This is in agreement with a recent survey by the International Obesity Task Force for the World Health Organization indicating that around $36 \%$ of children between the ages of 7 and 11 in Italy and Sicily are overweight or obese [22].

\section{Description of breakfast composition}

Most children (83.7\%) had breakfast whereas $16.3 \%$ reported absence of food and fluid intake at breakfast time. Food and fluid intake at breakfast and nature of fluids absorbed (water or other beverages such as juices, milk, tea, etc.) varied between participants (Table 2). Most of them (74.9\%) had food and beverages.

Total water intake (water coming from both fluid and food) of the entire cohort was $155.5 \pm 4.2 \mathrm{~mL}(\mathrm{n}=515)$ (Table 3). In children consuming both food and fluid $(\mathrm{n}=431)$, total water intake was 184.4 $\mathrm{ml}+2.2 \mathrm{~mL}$. Water came mostly from fluid consumption $(144.1 \pm 4.1$ $\mathrm{mL})$ as compared to food $(11.4 \pm 1.2 \mathrm{~mL})$. Furthermore, water came mostly from beverages other than drinking water $(133.6 \pm 3.7 \mathrm{~mL})$ rather than drinking water itself $(10.5 \pm 1.8 \mathrm{~mL})$. Only $7.6 \%$ of children

\begin{tabular}{|c|c|c|c|}
\hline & $\begin{array}{l}\text { Boys }(n=256) \\
\text { Mean }(C l ; S D)\end{array}$ & $\begin{array}{l}\text { Girls }(n=259) \\
\text { Mean }(\mathrm{Cl} ; \mathrm{SD})\end{array}$ & $\begin{array}{l}\text { All }(n=515) \\
\text { Mean }(I C ; S D)\end{array}$ \\
\hline \multicolumn{4}{|l|}{ Age (years) } \\
\hline $9 y$ & 72 & 57 & 129 \\
\hline $10 y$ & 109 & 94 & 203 \\
\hline $11 \mathrm{y}$ & 75 & 108 & 183 \\
\hline Body Weight (kgs)* & $38.5(23-75 ; 8.2)$ & $37.1(23-70.5 ; 7.9)$ & $37.8(23-75 ; 8.1)$ \\
\hline$<30 \mathrm{~kg}$ & 25 & 37 & 62 \\
\hline $30-39 \mathrm{~kg}$ & 123 & 127 & 250 \\
\hline $40-49$ & 81 & 56 & 137 \\
\hline$\geq 50$ & 22 & 24 & 46 \\
\hline Body Height $(\mathrm{cm})^{*}$ & $144.5(120-168 ; 8.1)$ & $144.5(100-165 ; 8.7)$ & $144.5(100-168 ; 8.4)$ \\
\hline BMI $\left(\mathrm{kg} / \mathrm{m}^{2}\right)^{*}$ & $18.3(11.1-26.7 ; 2.8)$ & $17.7(12.8-35 ; 2.9)$ & $18.0(11.1-35 ; 2.9)$ \\
\hline $\mathrm{BMI}<13,5 \mathrm{Kg} / \mathrm{m}^{2}$ & 1 & 7 & 8 \\
\hline $13,5<\mathrm{BMI}<17 \mathrm{Kg} / \mathrm{m}^{2}$ & 80 & 100 & 180 \\
\hline $17<\mathrm{BMI}<20 \mathrm{Kg} / \mathrm{m}^{2}$ (overweight) & 99 & 85 & 184 \\
\hline $20 \mathrm{Kg} / \mathrm{m}^{2}<\mathrm{BMI}$ (obese) & 63 & 45 & 108 \\
\hline
\end{tabular}

Means values are given with (confidence interval, standard deviation SD); *Body weight values were documented for 251 boys and 244 girls, body height values for 245 boys and 245 girls and BMI values for 240 boys and 237 girls

Table 1: Demographic and physical characteristics of the cohort $(n=515)$.

\begin{tabular}{|c|c|c|c|c|c|c|c|}
\hline & \multicolumn{3}{|l|}{ No Food } & \multicolumn{4}{|l|}{ Food } \\
\hline & No Fluid & Only beverages other than water & All fluids & No Fluid & Only beverages other than water & Only water & All fluids \\
\hline Boys & 44 & 13 & 0 & 8 & 174 & 5 & 12 \\
\hline Girls & 40 & 15 & 1 & 8 & 174 & 5 & 16 \\
\hline All $=515$ & 84 & 28 & 1 & 16 & 348 & 10 & 28 \\
\hline All (in \%) & $16.3 \%$ & $5.5 \%$ & $0.2 \%$ & $3.1 \%$ & $67.5 \%$ & $1.9 \%$ & $5.5 \%$ \\
\hline
\end{tabular}

Table 2: Number of children by diet clusters ( $n=515)$.

\begin{tabular}{|c|c|c|c|c|c|c|c|c|}
\hline & \multicolumn{3}{|c|}{ No Food } & \multicolumn{4}{|l|}{ Food } & \multirow[b]{2}{*}{$\begin{array}{l}\text { Means for the } \\
\text { entire cohort }\end{array}$} \\
\hline & $\begin{array}{l}\text { No } \\
\text { Fluid } \\
(n=84)\end{array}$ & $\begin{array}{l}\text { Only beverages } \\
\text { other than water } \\
(n=28)\end{array}$ & $\begin{array}{l}\text { All fluids (plain } \\
\text { waterANDother } \\
\text { beverages) } \\
(n=1)\end{array}$ & $\begin{array}{l}\text { No Fluid } \\
(n=16)\end{array}$ & $\begin{array}{l}\text { Only beverages } \\
\text { other than water } \\
(n=348)\end{array}$ & $\begin{array}{l}\text { Only plain } \\
\text { water } \\
(n=10)\end{array}$ & $\begin{array}{l}\text { All fluids (plain water AND } \\
\text { other beverages) } \\
(n=28)\end{array}$ & \\
\hline $\begin{array}{l}\text { Plain water (mineral, } \\
\text { spring, tap) (ml) }\end{array}$ & 0 & 0 & 199.8 & 0 & 0 & $139.8 \pm 13.6$ & $136.4 \pm 12$ & $10.5 \pm 1.8$ \\
\hline $\begin{array}{l}\text { water in other beverages } \\
\text { (ml) }\end{array}$ & 0 & $160.9 \pm 7.1$ & 177 & 0 & $170.4 \pm 2.8$ & 0 & $171.3 \pm 11.7$ & $133.6 \pm 3.7$ \\
\hline water from food (ml) & 0 & 0 & 0 & $89.3 \pm 17.1$ & $10.8 \pm 1.2$ & $40.9 \pm 15.6$ & $9.4 \pm 4.1$ & $11.4 \pm 1.2$ \\
\hline water from all fluids (ml) & 0 & $160.9 \pm 7.1$ & 376.8 & 0 & $170.4 \pm 2.8$ & $139.8 \pm 13.6$ & $307.7 \pm 17.5$ & $144.1 \pm 4.1$ \\
\hline Total water (ml) & 0 & $160.9 \pm 7.1$ & 376.8 & $89.3 \pm 17.1$ & $181.2 \pm 3.2$ & $180.7 \pm 15$ & $317.1 \pm 18.1$ & $155.5 \pm 4.2$ \\
\hline Protein (g) & 0 & $4.8 \pm 0.5$ & 7 & $6.7 \pm 1.9$ & $8.9 \pm 0.2$ & $4.5 \pm 0.6$ & $9.5 \pm 0.8$ & $7.1 \pm 0.2$ \\
\hline Lipid (g) & 0 & $3.4 \pm 0.6$ & 3 & $8 \pm 1.6$ & $8.6 \pm 0.3$ & $6.1 \pm 0.5$ & $9 \pm 1$ & $6.9 \pm 0.2$ \\
\hline Carbohydrate (g) & 0 & $9.8 \pm 0.9$ & 10 & $35.9 \pm 5.8$ & $48 \pm 1.2$ & $28.7 \pm 4.1$ & $45.4 \pm 4.1$ & $37.1 \pm 1.2$ \\
\hline Energy (Kcal) & 0 & $86.7 \pm 7.8$ & 92 & $236 \pm 41$ & $292.9 \pm 6.5$ & $180.4 \pm 18.2$ & $289.4 \pm 24.9$ & $229.4 \pm 6.9$ \\
\hline Sodium (mg) & 0 & $68.9 \pm 7.8$ & 93.5 & $\begin{array}{l}211.7 \pm \\
61.6\end{array}$ & $187.7 \pm 5.8$ & $126.9 \pm 20$ & $208.8 \pm 24.1$ & $151.2 \pm 5.6$ \\
\hline Potassium (mg) & 0 & $239.3 \pm 21.9$ & 340.2 & $\begin{array}{l}222.8 \pm \\
40.5\end{array}$ & $339.9 \pm 8.5$ & $137.6 \pm 30.4$ & $351.2 \pm 26.5$ & $272.1 \pm 8.3$ \\
\hline Phosphorus (mg) & 0 & $134.2 \pm 14.7$ & 188 & $\begin{array}{l}126.5 \pm \\
29.1\end{array}$ & $197.6 \pm 5.4$ & $92 \pm 17.5$ & $212.4 \pm 17.6$ & $158.5 \pm 5.1$ \\
\hline PRSL & 0 & $39.1 \pm 4.2$ & 56 & $55.3 \pm 15$ & $71.2 \pm 1.7$ & $36 \pm 4.2$ & $76.1 \pm 6.1$ & $56.9 \pm 1.8$ \\
\hline
\end{tabular}

Table 3: Breakfast composition, mean \pm SEM. 
consumed drinking water at breakfast $(\mathrm{n}=39)$. Among them, only 1.9 $\%(\mathrm{n}=10)$ drank solely drinking water.

Breakfast provided $229.4 \pm 6.9$ kilocalories on average. This is below the 500 kilocalories corresponding to $25 \%$ of daily kilocalorie intake recommended for breakfast in children at this age [23]. The main breakfast macronutrient was carbohydrate $37.1 \pm 2 \mathrm{~g}$ ). Protein intake was slightly higher in children eating and drinking $(7.1 \pm 0.12$ g) compared to children only eating $(6.7 \pm 1.9 \mathrm{~g})$. Sodium intake corresponded to $10 \%$ of the recommended daily intake (188.62 \pm 5.17 $\mathrm{mg}$ ) which should be $2 \mathrm{~g}$ at this age [23].

\section{Urine osmolality}

The mean urine osmolality for the entire cohort was $875.5 \pm 232.2$ $\mathrm{mosmol} / \mathrm{kg}$. Distribution of osmolality values was very large across the sample of children and the median value was $906 \mathrm{mosmol} / \mathrm{kg}$, not very much higher than the mean urine osmolality. $67.2 \%$ of the children $(\mathrm{n}=346)$ had a urine osmolality above $800 \mathrm{mosmol} / \mathrm{kg}$. Among them, $35.0 \%$ had a urine osmolality above $1000 \mathrm{mosmol} / \mathrm{kg}$. Differences between girls and boys were observed for almost the entire range of osmolality distribution $(\mathrm{p}<0.001)$ (Figure 1 ). Girls more frequently had a urine osmolality between 100 and $800 \mathrm{mosmol} / \mathrm{kg}$. The greatest difference was observed for osmolality values between 800 and 1100 mosmol/kg: elevated urine osmolality was significantly more common in boys than in girls $(71.9 \%$ vs $62.5 \%, \mathrm{p}=0.02)$.

\section{Determinants of urine osmolality}

Physical characteristics of children such as weight and height did not contribute to urine osmolality (Table 4 ), in contrast to gender difference which was confirmed $(\mathrm{p}<0.01)$. None of the various breakfast dietary variables was significantly associated with urine osmolality. There was a trend for an inverse association between total water intake and urine osmolality.

When investigating contribution of various water sources to urine osmolality by multiple linear regression, total water intake was significantly and inversely associated to urine osmolality of children $(p<0.05)$ suggesting that the less the children drank, the higher their urine osmolality. Water coming from fluids was also inversely and significantly associated to urine osmolality in contrast to water coming from food. Finally, we observed a trend for an inverse association between both water coming from water and water coming from other beverages and urine osmolality (Table 5 ).

We then tested the relationship between water intake and urine osmolality by logistic regression using a $1000 \mathrm{mosmol} / \mathrm{kg}$ cut-off. We observed again a trend, for an association between water coming from beverages other than plain water and a urine osmolality above 1.000 $\mathrm{mosmol} / \mathrm{kg}$. The same was true for water coming from plain water only.

\section{Discussion}

In the present study, we investigated the prevalence of elevated morning urine osmolality in a large sample of 515 Italian children aged 9 to 11 years attending primary school. Our main finding is that $67.2 \%$ of children had a urine osmolality over $800 \mathrm{mosmol} / \mathrm{kg}$ of water and among them, $35.0 \%$ had a urine osmolality over $1000 \mathrm{mOsmol} / \mathrm{kg}$. This was more frequent in boys than in girls (71.9\% versus $62.5 \%)$.

Previous studies investigated hydration status in children by measuring urine osmolality either for 24 hours [13] or at a given time point $[24,16]$. Here, we decided to measure urine osmolality at least 30 minutes after breakfast. Morning urine before breakfast is concentrated and reflects the fasting state and water restriction that occur during nighttime sleep [25]. Food and fluid intake at breakfast should lead to rehydration. It was therefore interesting to investigate whether total water intake at breakfast is sufficient to compensate water loss during the night in children.

In the present study, we found that $67.2 \%$ of children had a urine osmolality over $800 \mathrm{mosmol} / \mathrm{kg}$ of water and among them, $35 \%$ had a urine osmolality over $1000 \mathrm{mosmol} / \mathrm{kg}$. To our best knowledge, no studies investigating urine osmolality in Italian schoolchildren have been performed. The elevated urine osmolality values observed in our study indicate that, despite water intake at breakfast, the children's urine was still concentrated. The kidney has to concentrate urine to counteract an increase in plasma osmolality. One explanation may be that breakfast fluid intake did not suffice to compensate for dehydration

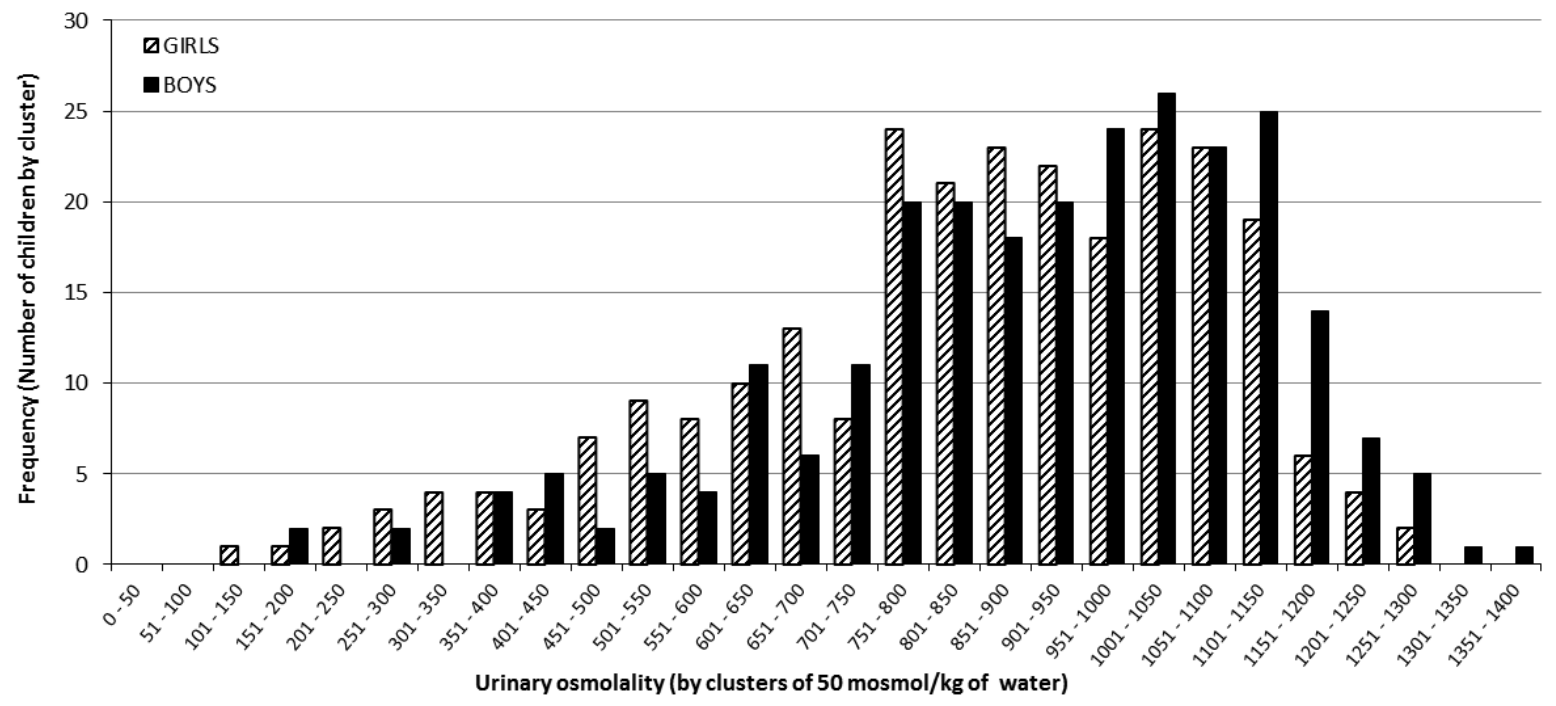

Figure 1: Distribution of urinary osmolality by clusters of 50 mosmol $/ \mathrm{kg}$ of water in italian schoolchildren ( $\mathrm{n}=259 \mathrm{girls}$ and $\mathrm{n}=256 \mathrm{boys}$ ). 


\begin{tabular}{|l|l|l|}
\hline Variables & $\beta$ coefficient & P value \\
\hline Sex $($ Boy $=1)$ & $68.3^{1}$ & $<0.01$ \\
\hline Age & 4.4 & 0.79 \\
\hline Height & 0.03 & 0.93 \\
\hline Weight & -0.52 & 0.64 \\
\hline Kilocalories & 2.56 & 0.78 \\
\hline Total fluid intake & -0.28 & $<0.07$ \\
\hline Protein & -8.2 & 0.83 \\
\hline Lipid & -15.64 & 0.85 \\
\hline Carbohydrate & -9.89 & 0.78 \\
\hline Sodium & -0.17 & 0.28 \\
\hline Potassium & -0.31 & 0.14 \\
\hline Phosphorus & 0.4 & 0.31 \\
\hline
\end{tabular}

$\beta$ coefficient values derived from the multiple regression analysis are given \pm standard deviation ${ }^{1}$ : pvalue $<1 \%$

Table 4: Correlation between cohort characteristics and breakfast dietary variables with urine osmolality in Italian children aged 9 to 11 years.

\begin{tabular}{|l|l|l|}
\hline & All children & Drinkers only \\
\hline Sex (boy=1) & $75.0^{a}$ & $84.3^{a}$ \\
\hline Age & 13.3 & 19.3 \\
\hline Height & -0.05 & -0.29 \\
\hline Weight & -0.74 & -0.37 \\
\hline Kcalories & 0.07 & 0.06 \\
\hline Water in fluid - Plain water & -0.44 & -0.45 \\
\hline Water in fluids -Beverages other than plain water & -0.27 & -0.31 \\
\hline Water in food & -0.00 & 0.14 \\
\hline
\end{tabular}

$\beta$ coefficient values derived from multiple regression analysis are given \pm standard deviation. apvalue $<1 \%$

Table 5: Correlation between cohort characteristics and intake of water from various sources with urine osmolality in Italian children aged 9 to 11 years.

during the night. Prevalence of mild dehydration observed in this Italian samples is quite similar to the prevalence reported by Bonnet et al. (62\%) [14] in the French sample and by Stookey et al. in the American sample (63 in Los Angeles and 66\% in New York City) [15].

When analyzing the determinants of urine osmolality in children, we found that total water intake was significantly and inversely correlated with urine osmolality. The amount of water ingested at breakfast via food and fluid intake had an impact on the dilution of urine. The significant association between water intake coming from fluids and urine osmolality shows that beverages absorbed at breakfast impacted children hydration status in contrast to food which brought little water to the body. A majority of the children (98.6\%) drank less than $400 \mathrm{~mL}$ at breakfast and had a higher probability of having a high osmolality after breakfast than children with a higher total water intake. This is in line with the observations of Bellisle et al. who suggest that water intake among French children may not be sufficient to maintain an adequate hydration status [9]. It seems to be also the case in Italian children. These findings suggest that higher fluid intake at breakfast should be recommended for children.

Interestingly, elevated urine osmolality was more frequent in boys than girls. This gender difference has been observed in previous studies in children and adults $[26,27,8]$. Total water intake and breakfast osmotic load was quite similar in both groups. Water intake coming from food and beverages was similar for both sexes. This difference in urine osmolality between genders has to be further investigated.

In conclusion, this study on a large cohort of Italian schoolchildren shows for the first time that almost two-thirds of children have evidence of a hydration deficit when they go to school in the morning, despite breakfast intake. Their fluid intake at breakfast does not suffice to maintain an adequate hydration status for the whole morning.

Keynote: Urinary osmolarity was measured after breakfast intake in a large cohort of 515 Italian schoolchildren aged 9-11 years. More than two thirds of the children (67.2\%) had a urine osmolality above $800 \mathrm{mosmol} / \mathrm{kg}$. This was more frequent in boys (71.9\%) than in girls (62.5\%). Such prevalence of hydration deficit suggests that fluid intake at breakfast does not suffice to maintain an adequate hydration status for the whole morning.

\section{Acknowledgments}

This study was sponsored by Nestlé Waters.

\section{References}

1. Wells JC, Fewtrell MS, Davies PS, Williams JE, Coward WA, et al. (2005) Prediction of total body water in infants and children. Arch Dis Child 90: 965971.

2. Pratt EL, Bienvenu B, Whyte MM (1948) Concentration of urine solutes by young infants. Pediatrics 1: 181-187.

3. Ballauff A, Kersting M, Manz F (1988) Do children have an adequate fluid intake? Water balance studies carried out at home. Ann Nutr Metab 32: 332 339.

4. Consolazio CF, Matoush LO, Johnson HL, Krywicki HJ, Isaac GJ, et al. (1968) Metabolic aspects of calorie restriction: hypohydration effects on body weight and blood parameters. Am J Clin Nutr 21: 793-802.

5. Goellner MH, Ziegler EE, Formon SJ (1981) Urination during the first three years of life. Nephron 28: 174-178.

6. EFSA Panel on Dietetic Products, Nutrition and Allergies (2010) Scientific opinion on dietary reference values for water. EFSA Journal 8: 1459-1507.

7. Jennifer J. Otten, Jennifer Pitzi Hellwig, Linda D. Meyers (2006) Dietary Reference Intakes: The Essential Guide to Nutrient Requirements. Institute of Medicine of National Academies, Washington DC, USA.

8. Ebner A, Manz F (2002) Sex difference of urinary osmolality in German children. Am J Nephrol 22: 352-355

9. Bellisle F, Thornton SN, Hebel P, Denizeau M, Tahiri M (2010) A study of fluid intake from beverages in a sample of healthy French children, adolescents and adults. Eur J Clin Nutr 64: 350-355.

10. Guariguet D (2008) Beverage consumption of Canadian adults. Component of Statistics Canada Catalogue 82-003-X.

11. Kant AK, Graubard BI (2010) Contributors of water intake in US children and adolescents: associations with dietary and meal characteristics--National Health and Nutrition Examination Survey 2005-2006. Am. J Clin Nutr 92: 887 896.

12. Montenegro-Bethancourt G, Vossenaar M, Doak CM, Solomons NW (2009) Total daily water intake in Guatemalan children. Food Nutr Bull 30: 340-350.

13. Manz F, Wentz A (2003) 24-h hydration status: parameters, epidemiology and recommendations. Eur J Clin Nutr 57 Suppl 2: S10-S18.

14. Bonnet F, Cathrin L, Lepicard EM, Constant F, Hawili N, et al. (2011) French children start their school day with an hydration deficit, Istanbul Congress Centre, Turkey.

15. Stookey JD, Brass B, Holliday A, Arieff A (2012) What is the cell hydration status of healthy children in the USA? Preliminary data on urine osmolality and water intake. Public Health Nutr 27: 1-9.

16. Bar-David Y, Urkin J, Kozminsky E (2005) The effect of voluntary dehydration on cognitive functions of elementary school children. Acta Paediatr. 94: 16671673.

17. Bar-David Y, Urkin J, Landau D, Bar-David Z, Pilpel D (2009) Voluntary dehydration among elementary school children residing in a hot arid environment. J Hum Nutr Diet 22: 455-460.

18. Bar-David Y, Gesundheit B, Urkin J, Kapelushnik J (2004) Water intake and cancer prevention. J Clin Oncol 22: 383-385. 
19. Bar-David Y (1998) Urine osmolality among elementary school children living in a hot climate: implications for dehydration. Ambulatory Child Health 23: 393397

20. Friis-Hansen B (1982) Water--the major nutrient. Acta Paediatr Scand Suppl 299: 11-16.

21. Cacciari E, Milani S, Balsamo A, Dammacco F, De LF, et al. (2002) Italian cross-sectional growth charts for height, weight and BMI (6-20 y). Eur J Clin Nutr 56: 171-180.

22. Lobstein T, Baur L, Uauy R (2004) Obesity in children and young people: a crisis in public health. Obes Rev 5 Suppl 1: 4-104.

23. Martin A (2001) Apports nutritionnels conseillés à la population française. (3rdedn), Tec \& Doc, France.
24. Bar-David Y, Landau D, Bar-David Z, Pilpel D, Philip M (1998) Urine osmolality among elementary school children living in a hot climate: implications for dehydration. Ambulatory Child Health 4: 393-397.

25. Van Hoeck K, Bael A, Lax H, Hirche H, Van Gool JD (2007) Circadian variation of voided volume in normal school-age children. Eur J Pediatr 166: 579-584.

26. Skinner R, Cole M, Pearson AD, Coulthard MG, Carft AW (1996) Specificity of $\mathrm{pH}$ and osmolality of early morning urine sample in assessing distal renal tubular function in children: results in healthy children. BMJ 312: 1337-1338.

27. Kutz FW, Cook BT, Carter-Pokras OD, Brody D, Murphy RS (1992) Selected pesticide residues and metabolites in urine from a survey of the U.S. general population. J Toxicol Environ Health 37: 277-291. 